\title{
A EXPERIÊNCIA CANADENSE NA PERSPECTIVA DO EMPREENDEDORISMO IMIGRANTE BRASILEIRO EM TORONTO
}

Michel Mott Machado ${ }^{1}$

Caroline Shenaz Hossein ${ }^{2}$

Eduardo $\mathrm{Cruz}^{3}$

Roberto Pessoa De Queiroz Falcão ${ }^{3}$

\footnotetext{
${ }^{1}$ Unidade do Ensino Superior de Graduação (CESU, Adm. Central) / Centro Estadual de Educação Tecnológica Paula Souza (CEETEPS)

${ }^{2}$ Depart. of Social Science - Business \& Society Program / Faculty of Liberal Arts \& Professional Studies / York University ${ }^{3}$ Departamento de Empreendedorismo e Gestão / Faculdade de Administração e Ciências Contábeis / Universidade Federal Fluminense
} 


\section{A EXPERIÊNCIA CANADENSE NA PERSPECTIVA DO EMPREENDEDORISMO IMIGRANTE BRASILEIRO EM TORONTO ${ }^{1}$}

Resumo: objetivou-se analisar o perfil sociodemográfico do empreendedorismo imigrante brasileiro em Toronto, seus traços comportamentais empreendedores, além dos negócios em si. A pesquisa é de natureza qualitativa e do tipo exploratório-descritiva, bibliográfica e de campo. A maioria se declarou proveniente do Sudeste brasileiro, branca, de 35 a 49 anos, casada, com filhos, background acadêmico e profissional elevados. A influência do estado de mal-estar social no Brasil e do discurso oficial canadense, parecem atuar como fatores de "expulsãoatração" à migração. A condição laboral da chegada, pode "empurrar" para o empreendedorismo por necessidade, embora também se verifique movimento para empreender por oportunidade. Os negócios, majoritariamente, são de pequeno porte, atuam no setor de prestação de serviços, com destaque à concentração em West End. Percebeu-se, em vários negócios, uma forte busca de identificação com a própria comunidade étnica, o que sugere formação de 'economia de enclave', porém em alguns casos visava-se o mercado mainstream.

Palavras-chave: Empreendedorismo Imigrante. Brasileiros. Toronto. Canadá.

\section{$1 \quad$ Introdução}

O debate referente à imigração tem se tornado cada vez mais relevante e presente, principalmente devido à grande movimentação de refugiados africanos e sírios rumo a Europa (SALGADO, 2018; GÓIS, 2018; FIGUEIRA, 2018), assim como pelo polêmico discurso do então candidato e agora presidente dos Estados Unidos da América (EUA), Donald Trump, dando ênfase à "questão mexicana" naquele país (PIÑEIRO; LANDA, 2018; VEDOVATO, 2018). No Brasil, diversas questões relativas à imigração haitiana (BAENINGER, 2018) e venezuelana (SIMÕES, 2018; MOREIRA, 2018) têm chamado a atenção.

Apesar dos movimentos migratórios serem um fenômeno antigo, a discussão das consequências para os países anfitriões tem se tornado intensa ao longo dos anos. Estudos têm apontado para os impactos sociais e econômicos desses grandes fluxos migratórios (TRENZ; TRIANDFYLLIDOU, 2017; SCHIMMELE; WU, 2015; SUMMERS, 2015; XIE; GOUGH, 2011).

Constata-se que o final do séc. XX e o início do séc. XXI trouxe profundas transformações em âmbito internacional, sendo que as mudanças oriundas do processo de reestruturação produtiva, produziu implicações à mobilidade de capital e de pessoas em diferentes partes do globo (SASSEN, 1988). Nesta direção, se tem defendido a ideia de que tais fluxos redesenham os países nos espaços migratórios na divisão internacional do trabalho (DE HASS, 2010), portanto, "à medida que as localidades se inserem na lógica global, as migrações internacionais tenderão a se intensificar" (BAENINGER, 2018, p. 464).

\footnotetext{
${ }^{1}$ O presente artigo é um desdobramento do projeto de pesquisa, "Brazilian Immigrant Entrepreneurship in Toronto". O referido projeto, em andamento, conta com o apoio da Fundação de Amparo à Pesquisa do Estado de São Paulo - FAPESP (Processo 2018/11276-0).
} 
Assim, tendo em vista que nem todos os imigrantes possuem qualificação profissional ou recursos financeiros para realizarem uma trajetória regular, muitos desses migrantes usam dos meios possíveis para chegar ao objetivo de morar em outro país (CRUZ; FALCÃO; BARRETO, 2018). Neste sentido, a academia tem apontado para o empreendedorismo como uma das formas de ascensão econômica do imigrante (CRUZ; FALCÃO; BARRETO, 2017; PORTES; ZHOU, 1992).

Há evidências de que o interesse pelo tema "Ethnic and Immigrant Entrepreneurship", no plano internacional, parece estar em crescimento (CRUZ; FALCÃO, 2016; MA et al., 2013). No Brasil, apenas recentemente tem se verificado alguns estudos voltados ao assunto, tendo por foco a literatura acadêmica produzida sobre o tema (CRUZ; FALCÃO, 2016), o empreendedorismo imigrante de brasileiros fora do Brasil (CRUZ; FALCÃO; BARRETO, 2018; FALCÃO et al., 2018; CRUZ, FALCÃO; BARRETO, 2017; CRUZ et al., 2017), bem como sobre o empreendedorismo imigrante de estrangeiros no país (CRUZ; MANCEBO; FALCÃO, 2018).

Ao se olhar para o recente cenário de crise político-institucional e econômica no Brasil, com severos reflexos no âmbito social, verifica-se um movimento de intensificação da emigração de brasileiros para o exterior (BRASIL, 2016). Dentro desse contexto, o Canadá tem se apresentado como um importante destino de migração brasileira (IDEM).

Estudos precursores procuraram analisar o fenômeno da imigração brasileira para a América do Norte (GOZA, 1994; MARGOLIS, 1994; 2013), em geral, bem como para o Canadá (GOZA, 1999), em particular. No entanto, do ponto de vista temático do "empreendedorismo imigrante e étnico brasileiro", particularmente no Canadá, reconhece-se que pouco se sabe até o momento, para dizer o mínimo. Assim, ao se considerar o aumento consistente da população brasileira imigrante nesse país, além da ampla lacuna do conhecimento sobre suas atividades e características empreendedoras (MACHADO; HOSSEIN; CRUZ, 2019; MACHADO; HOSSEIN, 2018), considera-se relevante analisar os padrões do empreendedorismo imigrante brasileiro no Canadá. Portanto, este artigo objetivou analisar aspectos relativos ao perfil sociodemográfico da "comunidade" empreendedora brasileira em Toronto, seus traços comportamentais empreendedores, além dos negócios em si.

Do ponto de vista teórico, o presente trabalho visa contribuir à ampliação do entendimento da estruturação dos negócios de imigrantes brasileiros, seus fatores relacionados e condicionantes; em uma perspectiva prática, visa-se trazer uma contribuição para que empreendedores/as imigrantes brasileiros/as compreendam os significados e a abrangência do tema tratado, a fim de que possam atuar com maior precisão na gestão dos negócios.

\section{Evolução do Conhecimento sobre Empreendedorismo Étnico e Imigrante}

Inicialmente, pontue-se que autores como Bonacich (1973) e Light, Bhachu e Karageorgis (1990), diferenciam os termos "imigrante" e "grupo étnico" da seguinte maneira: (i) o imigrante é aquele que migrou ou estrangeiro pertencente à primeira geração; (ii) os indivíduos pertencentes a uma minoria étnica (os próprios imigrantes ou seus descendentes) são tratados como grupo étnico. Essa distinção se faz pertinente, uma vez que a literatura sobre a ação empreendedora desses grupos traz uma distinção entre "Immigrant Entrepreneurship" e "Ethnic Entrepreneurship". 
De um modo geral, os estudos voltados ao empreendedorismo étnico e imigrante, apresentamse caracteristicamente em interação disciplinares (CRUZ; FALCÃO, 2016; MA et al., 2013; ALIAGA-ISLA; RIALP, 2013). Ademais, esses autores apontaram para algumas áreas formadoras deste campo, identificando a preponderância da sociologia em seus primórdios, e posteriormente, da geografia. Mais recentemente, se tem verificado a análise dos aspectos sociológicos e econômicos, amparada no uso da teoria dos capitais de Bourdieu (1986) e na análise comparativa da geração de renda dos diversos grupos étnicos. Nesta direção, alguns autores foram cruciais na criação e conformação dessas linhas de investigação (ALBA; NEE, 2014; ZHOU, 2004; ALBA; LOGAN, 1993; PORTES; ZHOU, 1992).

Em uma publicação que se tornou referencial, Rath (2000) procurou demonstrar os principais direcionamentos dentro do campo denominado "Immigrant Businesses", dando-se destaque às dimensões econômica, político-institucional e do ambiente social. Nesta direção, as principais correntes de estudo podem ser assim definidas: "Ethnic Minorities and Enclaves"(ver WERBNER, 1980; BONACICH, 1973); "Disadvantage in the Labour Market and SelfEmployment" (ver PORTES; ZHOU, 1992; LIGHT, 1979); "Ethnic Entrepreneurship" (ver BONACICH, 1993; WALDINGER et al., 1990;); "Interactive Model" ou "Integrative Approach (economic/institutional)" (ver LIGHT; ROSENSTEIN, 1995; WALDINGER et al., 1990); "Political Economy of Immigrant Businesses"(ver SASSEN, 1991); e "Immigrant Business and the Role of Government" ou "Politico-Institutional Framework" (ver BONACICH, 1993).

Tem sido destacado como um desafio da pesquisa dentro do campo, o caráter multidisciplinar do tema, além de ter sido identificado que os estudos não utilizavam teoria específica alguma (ALIAGA-ISLA; RIALP, 2013). Apesar disso, é possível apontar algumas proposições teóricas abordadas: (i) teorias do capital humano - para analisar as características dos imigrantes; (ii) teoria cognitiva social - para estudar a influência do ambiente social na busca de oportunidades empreendedoras; (ii) teoria do social - para investigar semelhanças entre os empresários imigrantes localizados em diferentes regiões; (iv) cultura nacional - para compreender dimensões individualistas e coletivistas; (v) teorias de interseccionalidade e a perspectiva psicológica - para analisar o comportamento empreendedor das mulheres imigrantes (IDEM). Ma et al. (2013), por sua vez, realizaram estudo em um conjunto de 403 artigos e identificaram os principais temas de pesquisa na literatura de empreendedorismo étnico entre 1999 e 2008, os quais versavam sobre economias de enclaves, empresas étnicas, inserção social dos empreendedores imigrantes, redes de imigrantes e empreendedores transnacionais. Os autores afirmaram que o debate do empreendedorismo étnico gira em torno da figura dos 'empresários imigrantes', nas 'redes de negócios imigrantes' e nos 'empresários transnacionais'.

A partir de uma revisão bibliométrica, a partir de literatura de 1980 a 2016, Cruz e Falcão (2016) apresentaram os principais autores, assuntos pesquisados e seus respectivos departamentos de origem, entre outras categorias de análise. Ainda segundo esses autores, devido à repercussão de suas contribuições, alguns pesquisadores têm norteado a discussão dentro do campo, por exemplo, por meio da teoria da assimilação e auto emprego (PORTES; ZHOU, 1992), bem como as questões culturais e da ecologia organizacional (EVANS; LEIGHTON, 1989).

Outros estudos buscaram analisar modelos teóricos complementares de assimilação espacial e estratificação por localização (ICELAND; WILKES, 2006; ALBA; LOGAN, 1993), trabalhos estes que trataram aspectos relacionados ao campo da geografia e dos estudos urbanos. 
Acrescente-se que os mecanismos de sobrevivência originários da ecologia organizacional, estudados na sociologia e na área de administração, também são discutidos a partir de diversas etnias, assim como sobre a questão de gênero no empreendedorismo (CRUZ; FALCÃO, 2016). Estudos como o de Nee, Sanders e Sernau (1994), por sua vez, mostram tendências de alguns imigrantes que se afastam dos subempregos ligados à economia étnica mais informalizada, buscando trabalhos formais fora do enclave, seja devido ao grau de educação, bem como a outros fatores culturais.

Outros trabalhos têm sido direcionados a examinar os mercados étnicos (LOGAN; ALBA; McNULTY, 1994), assim como o transnacionalismo (PORTES; GUARNIZO; HALLER, 2002), fenômenos estes tidos como uma forma alternativa de adaptação econômica de minorias étnicas nas sociedades. Esses estudos, percebe-se, têm se baseado na teoria de redes aplicadas ao contexto transnacional.

Um fator chave identificado para o empreendedorismo étnico e imigrantes transnacional é o que se chamou de formação de redes ou networking, uma vez que funciona, concomitantemente, como um mecanismo de apoio e um direcionador na seleção de destinos e oportunidades de negócios (CRUZ; FALCÃO; BARRETO, 2018). Nesta linha, se tem verificado a ocorrência de três formas de formações de rede/networking, quais sejam: as redes de origem (étnica, nacional), as redes de destino e as redes da indústria, também denominadas 'rede de prática' (DRORI; HONIG; WRIGHT, 2009). Além disso, verificou-se que as redes formadas nos 'enclaves étnicos', reduzem as barreiras para a emigração, assim como aumentam as oportunidades econômicas, de modo a aproveitar os recursos para o estabelecimento de negócios relacionados aos imigrantes (CRUZ; FALCÃO; BARRETO, 2018; DRORI; HONIG; WRIGHT, 2009).

De acordo com Zhou (2004), existem três categorias básicas de empreendedorismo étnico: (i) a 'minoria intermediária' ou 'middlemen minority' - formação que desempenha uma posição intermediária entre o grupo dominante e os indivíduos do enclave, sendo geralmente representadas pelos proprietários de pequenas empresas; (ii) os 'nichos de mercado étnico' representada por negócios intensivos em mão de obra, de baixa lucratividade, fornecedores de "produtos exóticos" para os mercados tradicionais, além de estarem voltados a diversos setores da economia em bairros mais pobres; (iii) as 'economias de enclave' - funciona como uma entidade cultural integrada, possuidora de fortes laços de solidariedade/'coetnicidade', acesso privilegiado ao capital financeiro informal e à força de trabalho étnica, além de, geralmente, estarem concentradas geograficamente.

Ainda na perspectiva do empreendedorismo étnico, considere-se que as necessidades étnicas específicas, podem criar um nicho de mercado dentro da comunidade (LIGHT, 1972), vindo a promover barreiras à entrada de concorrentes (MASUREL et al., 2002). Acrescente-se, também, a possibilidade de existir formas não convencionais de abastecimento e de distribuição (WILSON; PORTES, 1980), bem como o suprimento de capitais financeiros alternativos (GREENE, 1997).

Algumas comunidades étnicas se estabelecem em uma determinada localização geográfica, o que pode vir a promover um ecossistema de empresas fornecedoras deste mercado étnico próprio (ZHOU, 2004). Outra possibilidade que se pode verificar, é a adoção de uma estratégia de fornecimento ao mercado principal (dominante) de um grande centro urbano (PORTES, 1981). 
Assim, em linhas gerais, pode-se considerar que há basicamente dois tipos de empreendedores imigrantes: os que são socialmente identificados com as suas comunidades étnicas e os que não se identificam com elas. Os primeiros, caracteristicamente, são mais propensos a se tornarem empreendedores do 'enclave étnico', pois tendem a se sentir mais ligados às suas comunidades por certos laços emocionais, culturais, por prestígio ou até mesmo pelo local de destino. Portanto, esses empreendedores buscam também melhorar sua comunidade até mesmo por meio de ações altruístas, chegando ao ponto de ajudar um futuro concorrente a se estabelecer neste mesmo enclave (LEE, 1999).

Acima de tudo, empreendedores imigrantes atendem as suas comunidades étnicas por meio de suas conexões, uma vez que, por meio delas, têm acesso a recursos essenciais. Nesta direção, quanto mais intensa a identificação com os seus grupos étnicos, mais propensos os empreendedores serão para o desenvolvimento de "estratégias de enclave" (ACHIDINDOFOR; PRIEM, 2011).

Estudos têm sido empreendidos à luz da abordagem teórica dos três tipos de capital: (i) social; (ii) humano; e (iii) econômico (ACHIDI-NDOFOR; PRIEM, 2011). Pensa-se que essa abordagem se mostra interessante, à medida em que para além de questões estritamente econômicas, remete-se para aspectos relacionados à educação formal, experiências profissionais e/ou empresariais, bem como à rede de relacionamentos profissionais do empreendedor imigrante. A esses três tipos de capital, acredita-se, poderia ser acrescentado o 'cognitivo', que tem a ver com a capacidade de aprender e de lidar com situações de maior complexidade/ambiguidade.

\section{Um Pouco sobre a Imigração Brasileira no Canadá}

Ao longo do tempo, é reconhecido que o Canadá tem visto na imigração um instrumento de promoção do seu crescimento demográfico e econômico, contudo, é de se notar que a atual política de imigração do país tem focalizado a atração de imigrantes com alta qualificação, bem como para o atendimento de funções carentes de mão de obra, posicionamento este que pode ser entendido diante de um contexto de maior inserção do país no comércio internacional e menor necessidade de se criar um grande mercado interno (FRAGA, 2018). Nesta direção, desde 2002, oficialmente o país tem definido três categorias básicas de residência permanente: (i) reunificações familiares; (ii) econômica; e (iii) humanitária (IDEM).

Assim, apesar do Canadá ser um país ainda requerente de imigrantes, bem como por ser reconhecido por ter adotado o multiculturalismo como uma política de Estado (CAMERON, 2004), o fenômeno migratório ainda se mostra como um objeto de tensões sociais, sendo uma de suas causas as barreiras de entrada ao mercado de trabalho (FRAGA, 2018). Neste tocante, a competência linguística em relação a uma das duas línguas oficiais do país (inglês e francês), ainda se mostra como um fator-chave à inserção no mercado de trabalho, além da dificuldade de ter o reconhecimento dos diplomas e experiências profissionais adquiridas antes da imigração (IDEM).

Em decorrência desses desafios destacadas, é possível supor que o empreendedorismo tem se mostrado como um importante meio de avanço econômico, uma vez que se sabe que imigrantes e certos grupos étnicos minoritários possuem maiores taxas de auto emprego do que a população dominante (HIEBERT, 2003). De fato, considera-se que no universo das pequenas e médias 
empresas, no Canadá, encontra-se uma importante diversidade social e cultural (GULATI, 2012).

É nesse contexto que se insere a imigração brasileira nesse país, considerando-se que não se trata de um fenômeno recente, mas de um fluxo migratório que tomou maior impulso a partir da segunda metade dos anos 1980 (SEGA, 2018). Segundo Goza (1999), o principal fator para a "diáspora" brasileira na década de 1980, deveu-se às crises política e econômica - a década perdida - no Brasil, sendo que esse fluxo de expulsão direcionado ao Canadá, continuou em crescimento depois da década de 1990 (SEGA, 2018). Seja como for, o Canadá tem se apresentado como um importante destino de migração brasileira, não exclusivamente por resultado da insegurança econômica no Brasil, mas de um estado de insegurança mais amplo (SCHERVIER, 2005).

Assim, ao se tomar por ano base 2013, já se estimava em 39.300 o número de brasileiros no país (BRASIL, 2016), sendo que em Toronto (Província de Ontário) se encontra o maior contingente de imigrantes brasileiros no Canadá (SEGA, 2018), população essa formada por vários níveis sociais distintos: membros da elite brasileira residente no Canadá há décadas e com fortes laços com a elite canadense; setor médio com alta escolaridade; trabalhadores do setor informal (SEGA, 2018; MARGOLIS 2013). Além disso, é sabido que a maioria dos newcomers brasileiros no Canadá encontram trabalho no setor informal, na maior parte em empreendimentos de portugueses, em diversos ramos de atividade: construção civil; serviços de limpeza; restaurantes; outros tipos de trabalhos de menor remuneração (MARGOLIS, 2013).

\section{$4 \quad$ Método}

Trata-se de uma pesquisa qualitativa - ainda em andamento - do tipo exploratório-descritiva, bibliográfica e de campo (VERGARA, 2007). As principais técnicas de coleta de dados utilizadas foram a observação assistemática (MINAYO, 2009), a aplicação de questionário e a entrevista semiestruturada (VERGARA, 2007).

Os critérios de escolha dos participantes foram os seguintes: (i) atuar como empreendedores(as), independentemente do ramo de atuação, do porte e da duração do negócio; (ii) ter tempo variado de estada no país; (iii) metade composto por homens e metade por mulheres, preferencialmente; (iv) idades variadas; (v) formação educacional/acadêmica variada.

Antes da chegada do pesquisador responsável a Toronto, notou-se a pertinência de incluir no rol de participantes, sujeitos que atuassem em instituições de apoio aos empreendedores imigrantes brasileiros no Canadá. Tal iniciativa, por várias razões se mostrou útil, pois foi possível obter informações sobre questões relacionadas à imigração e ao empreendedorismo transnacional, além de ser uma fonte de potenciais contatos para a pesquisa de campo no local de destino. Assim, uma primeira entrevista foi realizada ainda em São Paulo-SP, por meio da utilização de um roteiro de entrevista semiestrutura específico, isto é, com foco em sujeitos de instituições de apoio.

A etapa seguinte, consistiu no levantamento de dados secundários sobre os negócios e as localidades que mais concentram imigrantes brasileiros em Toronto, assim como o estudo bibliográfico sobre o tema de interesse. Para fins de identificação/confirmação de negócios de empreendedores/as imigrantes brasileiros/as, foi útil a realização de observação in loco, isto é, 
a prática de "caminhada" pelos locais de maior concentração de imigrantes brasileiros e a "conversa" com empreendedores locais para confirmar se o negócio, de fato, era de propriedade de empreendedores imigrantes brasileiros. Ademais, a partir da técnica de observação, foi possível perceber aspectos visíveis dos negócios (por ex.: utilização de símbolos que remetem à nacionalidade/naturalidade, à cultura brasileira, à língua portuguesa etc.). A utilização de um caderno de notas de campo foi extremamente útil para registrar impressões e insights dessas observações.

A verificação de propagandas em jornais e revistas voltada à "comunidade lusófona", principalmente os veículos dirigidos por brasileiros, foi uma fonte que se mostrou útil à prospecção de potenciais participantes da pesquisa, além de redes sociais - como LinkedIn e Facebook - que também foram utilizadas como fonte de acesso ao campo. Assim, uma vez identificados os negócios/empreendedores, estabelecia-se contato por meio de e-mail e/ou telefone e/ou rede social, a fim de efetivar o convite. Além disso, valeu-se da técnica snow-ball de amostragem (ATKINSON; FLINT, 2001).

Para a aplicação do questionário, utilizou-se o formulário eletrônico elaborado por meio da ferramenta Google Forms. Os itens norteadores do referido instrumento foram os seguintes: 1. Perfil sociodemográfico da "comunidade empreendedora brasileira"; 2. Decisão de deixar o Brasil; 3. Abertura da empresa no Canadá; 4. Conte sobre a empresa atual; 5. Conte sobre você. A amostra adotada para a survey foi do tipo não-probabilística e intencional (VERGARA, 2007).

Com vistas ao aprofundamento da compreensão sobre o fenômeno em foco, foram realizadas entrevistas semiestruturadas face a face, sendo as mesmas gravadas em áudio e, posteriormente, o seu conteúdo transcrito na íntegra. As entrevistas levavam cerca de 1 hora, sendo realizadas nos dias, locais e horários mais conveniente e oportunos para os sujeitos. Para a definição dos participantes desta etapa, adotou-se o critério de acessibilidade (VERGARA, 2007), tendo sido adotada novamente a técnica snow-ball. No que se refere à quantidade de participantes, nesta etapa da investigação, entendeu-se que não era o caso de se estabelecer um número aprioristicamente, uma vez que não se adotou uma amostra representativa e probabilística (BAUER; AARTS, 2002). As entrevistas tiveram como foco aspectos relacionados à experiência migratória dos participantes, suas experiências profissionais/empresariais, assim como questões atitudinais/comportamentais voltadas ao empreendedorismo, entre outros pontos.

Para a análise dos dados obtidos por meio da survey, utilizou-se a estatística descritiva simples, pelo menos neste momento; no que se refere à interpretação dos dados oriundos das entrevistas, utilizou-se o método de análise de conteúdo (BARDIN, 1977). Os resultados obtidos foram posteriormente confrontados com a literatura recente sobre o tema, a fim de concretizar os objetivos da pesquisa e de contribuir para o avanço do campo de estudo sobre o tema de interesse.

Resultados e Discussão

A amostra válida deste estudo foi de 44 (quarenta e quatro) participantes, sendo 3 (três) representantes de instituições de apoio ao empreendedorismo imigrante, dos quais 2 (dois) membros consulares e 1 (um) de entidade de caráter social/assistencial sem fins lucrativos, os 
outros 41 (quarenta e um) são empreendedores imigrantes brasileiros no Canadá, sendo que 27 (vinte e sete) dos quais, além de terem respondido o questionário, também foram entrevistados. Sobre ao perfil sociodemográfico dos participantes, tem-se que 70,73\% $(n=29)$ são do sexo feminino e $29,27 \%(\mathrm{n}=12)$ masculino, tendo $65,85 \%(\mathrm{n}=27)$ se autodeclarado branca e $24,39 \%$ $(\mathrm{n}=10)$ parda. A faixa etária predominante foi dos 35 a 63 anos (85\% dos participantes), sendo que $37,5 \%$ corresponde à faixa etária de 35 a 44 anos. Quanto a naturalidade, $36,58 \%(n=15)$ era de São Paulo (SP), 19,51\% $(n=8)$ de Minas Gerais $(M G), 14,63 \%(n=6)$ do Rio de Janeiro $(\mathrm{RJ})$ e 7,31\% (n=3) da Bahia (BA), entre outros estados brasileiros. As cidades onde a maioria dos participantes vivia antes de migrar para o Canadá, foram: São Paulo com 31,70\% (n=13), Rio de Janeiro com 14,63\% ( $\mathrm{n}=6)$ e Belo Horizonte com 9,75\% $(\mathrm{n}=4)$, no entanto, se fossem agregados mais 4 (quatro) participantes de outras cidades mineiras (Governador Valadares=2, Coronel Fabriciano=1 e Contagem=1), o estado de $M G$ iria para $19,51 \%$ no resultado de origem. Em relação ao estado civil, 63,41\% $(n=26)$ eram casados, 14,63\% $(n=6)$ divorciados e $12,19 \%$ solteiros $(n=5)$, sendo que de todos que chegaram a se casar $(n=35), 59,29 \%(n=19)$ casaram-se ainda no Brasil e 45,71\% $(\mathrm{n}=16)$ no exterior (a maioria no Canadá), além disso, $68,29 \%(\mathrm{n}=28)$ disseram ter filho(s).

Concernente ao que faziam no Brasil antes de migrar para o Canadá, 58,54\% $(\mathrm{n}=24)$ apontaram que eram empregados, 29,27\% $(n=12)$ que eram empresários e $12,19 \%(n=5)$ que não trabalhavam, sendo que dos se declararam empregados, 47,83\% $(n=11)$ sinalizaram que o último cargo ocupado, no Brasil, era de nível operacional (linha de frente), 39,13\% $(n=9)$ tático (gerencial) e 13,04\% $(n=3)$ estratégico (alto escalão).

Quanto ao nível de escolaridade, verificou-se que 43,90\% $(\mathrm{n}=18)$ dos respondentes era pósgraduada, $34,15 \%(n=14)$ graduada e $17,07 \%(n=7)$ formada no ensino médio-técnico. Em relação à proficiência em inglês e em francês, línguas oficiais do Canadá, temos: (i) inglês: $90 \%$ $(n=36)$ lê bem e 5\% $(n=2)$ razoavelmente, $85,36 \%(n=35)$ fala bem e $12,19 \% \quad(n=5)$ razoavelmente, $75,60 \%(n=31)$ escreve bem e $21,95 \%(n=9)$ razoavelmente, $92,5 \%(n=37)$ compreende bem e 7,5\% (n=3) razoavelmente; (ii) francês: $56,41 \%(\mathrm{n}=22)$ lê quase nada e $25,64 \%(\mathrm{n}=10)$ pouco, $58,97 \%(\mathrm{n}=23)$ fala quase nada e $28,20 \%(\mathrm{n}=11)$ pouco, $64,10 \%(\mathrm{n}=25)$ escreve quase nada e $25,64 \%(n=10)$ pouco, $52,63 \%(n=20)$ compreende quase nada e $28,94 \%$ $(\mathrm{n}=11)$ pouco.

Quando buscou-se saber sobre a decisão de deixar o Brasil, uma das principais motivações alegadas, tem a ver com a questão da "segurança", o que em alguns casos remete à "falta de segurança", à "sensação de insegurança", ou dá no mesmo, "violência", mas também à "instabilidade" para planejar a vida em um longo prazo, com melhor qualidade de vida, ou seja, tem-se aqui um olhar de "segurança" em um sentido mais amplo, conforme pontuado por Schervier (2005).

Outra característica sociodemográfica, tem a ver com a condição laboral na qual chegaram no Canadá. Nesta direção, 78,95\% $(\mathrm{n}=30)$ alegaram chegar "sem perspectiva de trabalho", 13,15\% $(\mathrm{n}=5)$ “já empresário(a)" e 7,90\% (n=3) “com emprego informal”, sendo que 87,80\% (n=36) se estabeleceram, pelo menos inicialmente, na cidade de Toronto. As razões mais frequentes para a escolha dessa cidade como local de residência, tem a ver com as "oportunidades de trabalho", também não sendo incomum o fator de "ter conhecidos, amigos ou parentes na cidade", o que, em alguma medida, pode ser um elemento de "segurança psicológica", de "não estar só", de "ter um apoio, se necessário". 
No que se refere ao tempo de estada no Canadá, tem-se que cerca de $26,83 \%(n=11)$ se encontram no país de 1 a 5 anos, 14,63\% $(n=6)$ de 6 a 13 anos, 19,51\% (n=8) de 14 a 19 anos, $29,27 \%(n=12)$ de 20 a 29 anos e $9,76 \%(n=4)$ de 30 a 39 anos.

No que tange a questão da experiência e do comportamento empreendedor dos participantes, pode-se dizer que para cerca de $45 \%(\mathrm{n}=18)$ o negócio aberto no Canadá era a sua primeira "empresa", 32,5\% $(\mathrm{n}=13)$ tiveram apenas 1 (uma) empresa e 22,5\% $(\mathrm{n}=9)$ tiveram de 2 (duas) ou mais empresas. Em relação à questão sobre terem escrito um plano de negócios antes de abrir a empresa/o negócio atual, 63,41\% $(n=26)$ responderam "não" e 36,59\% $(n=15)$ "sim"; já quando indagados se teriam desistido da ideia de ser um(a) empreendedor(a), se tivessem recebido uma proposta de emprego bem remunerado no Canadá, cerca de $76,92 \%(n=30)$ responderam "não" e 23,08\% (n=9) "sim", sendo que as principais explicações à resposta negativa tem a ver com a ideia de "estar a fazer o que se gosta", "ter mais liberdade de dispor do tempo", "maior autonomia" ou "Tô me divertindo!" (E13, 1 ano no Canadá). Quando perguntados(as) qual das duas ambições mais se parecia com a deles(as) antes de abrir a empresa/o negócio atual, cerca de 7,32\% (n=3) apontaram "ficar rico(a)" e 92,58\% (n=38) "materializar a empresa".

Ao serem questionados(as) se haviam pensado em ser empreendedor(a) no Canadá, antes de sair do Brasil, 68,29\% $(\mathrm{n}=28)$ responderam "não" e cerca de 31,71\% $(\mathrm{n}=13)$ "sim". Tais dados podem sugerir, juntamente com os $78,95 \%$ de chegada "sem perspectiva de trabalho", que uma parte considerável dos participantes pode ter decidido por empreender devido ao fator "necessidade".

Sobre algumas características dos negócios, nos quadros 1 e 2 são apresentados os resultados sobre os tipos de negócios desenvolvidos e os setores de atuação, respectivamente.

Quadro 1: tipo de negócio.

\begin{tabular}{|c|c|c|}
\hline Tipo de Negócio & Quantidade & $\mathbf{\%}$ \\
\hline Cooperativa & 1 & 2,44 \\
\hline Empresa familiar & 2 & 4,88 \\
\hline Parceria & 10 & 24,39 \\
\hline Próprio & 28 & 68,29 \\
\hline Total & $\mathbf{4 1}$ & $\mathbf{1 0 0}$ \\
\hline
\end{tabular}

Fonte: autoria própria.
Quadro 2: setor de atuação.

\begin{tabular}{|c|c|c|}
\hline Setor de Atuação & Quantidade & $\mathbf{\%}$ \\
\hline Comercial & 9 & 22,50 \\
\hline Comércio e Indústria & 3 & 7,50 \\
\hline $\begin{array}{c}\text { Comércio e Prestação de } \\
\text { Serviços }\end{array}$ & 2 & 5,00 \\
\hline Prestação de Serviços & 26 & 65,00 \\
\hline Total & $\mathbf{4 0}$ & $\mathbf{1 0 0}$ \\
\hline
\end{tabular}

Fonte: autoria própria.

Quando perguntados se o negócio estava a funcionar formalmente registrado, 87,81\% $(\mathrm{n}=36)$ responderam "sim" e 12,19\% $(\mathrm{n}=5)$ "não". Quanto ao porte do negócio, tomando-se como referência o número de empregados, $100 \%(\mathrm{n}=41)$ são small business, embora 6 (seis) deles não tivessem empregados, configurando-se, assim, como self-employment, situação essa que oficialmente impede de considerar essas empresas como small businesses (ISED, 2019). No que se refere ao ramo de atividade do negócio, destacaram-se: alimentos e bebidas, $(\mathrm{n}=7$ ou $17,07 \%)$, saúde e bem-estar ( $\mathrm{n}=7$ ou $17,07 \%)$, serviços de limpeza $(\mathrm{n}=4$ ou $9,76 \%)$ e serviços de consultoria ( $\mathrm{n}=3$ ou $7,32 \%$ ), entre outros.

$\mathrm{S}$ a origem do seed money do negócio, cerca de $85,71 \%(\mathrm{n}=36)$ indicaram "autofinanciamento" ou "recursos próprios", 7,14\% (n=3) "amigo" ou "família", 4,76\% $(\mathrm{n}=2)$ "crédito bancário" e 2,38\% (n=1) "pre seed money - hub da UofT". Quanto ao tempo médio para o retorno do 
investimento inicial, cerca de $46,15 \%(\mathrm{n}=18)$ responderam que retornou em até 1 ano, para $30,78 \%(n=12)$ o retorno ocorreu entre 1 ano e meio e 3 anos, sendo que para $20,51 \%(n=8)$ o retorno ainda não aconteceu. Sobre a origem dos recursos financeiros para a expansão dos negócios, cerca de $48 \%(\mathrm{n}=12)$ apontaram "autofinanciamento" ou "recursos próprios", $28 \%$ $(\mathrm{n}=7)$ "crédito bancário", $20 \%(\mathrm{n}=5)$ "lucro retido" e 4\% $(\mathrm{n}=1)$ "recursos governamentais"; quando indagados se era difícil ou uma restrição conseguir financiamento/empréstimo bancário para expandir os negócios, 66,67\% $(\mathrm{n}=20)$ disseram que "não" e 33,33\% $(\mathrm{n}=10)$ responderam "sim", sendo uma das principais razões, a "falta de histórico de crédito, pelo menos no início das atividades" (E26, 4 anos no Canadá), ou ainda "no início, para este tipo de negócio" (E27, 11 anos no Canadá).

No Canadá, em recente relatório do Innovation, Science and Economic Development Canada (ISED, 2019), fica evidente a relevância que as Small and Medium-Sized Enterprises (SMEs) tem na economia do país, seja no que se refere à geração de emprego e renda, à participação nas exportações e no Gross Domestic Product (GDP), entre outros indicadores. Portanto, os negócios dos empreendedores imigrantes brasileiros também se inserem nesse contexto, ou seja, numa dinâmica de contribuição para o desenvolvimento do país anfitrião.

Buscou-se, também, fazer uma análise da localização/concentração de negócios de imigrantes brasileiros na GTA (The Greater Toronto Area), sendo que 73,17\% $(\mathrm{n}=30)$ apontaram que o negócio se encontrava sediado em Toronto e 12,19\% (n=5) em Mississauga, as demais cidades indicadas (Oshawa, Vaughan, Durhan Region, Oakville, Richmond Hill e York Region), sediavam um negócio cada; já em termos de concentração dos negócios em Toronto, destacamse algumas localidades: (i) St. Claire Avenue West/Corso Italia-Davenport $(\mathrm{n}=4)$ e Earlscourt $(\mathrm{n}=3)$; (ii) Dundas Street West/Little Portugal $(\mathrm{n}=3)$. A região West End, da City of Toronto, tende a ser uma área com uma maior presença de negócios de imigrantes brasileiros, o que pode ser sugerido por se tratar de uma zona de reconhecida concentração brasileira.

Uma parte desse reconhecimento da localização/concentração, de certa forma já havia se dado por meio da utilização da técnica de observação in loco, dessas e de outras localidades. Foi possível verificar, portanto, que em vários dos negócios "visitados" - bem como outros que ainda não chegaram a participar do estudo - não era incomum a presença da bandeira brasileira na fachada ou o uso das suas cores e "feições", no entanto, em alguns casos, a bandeira nacional era substituída pela bandeira do estado de origem - normalmente vista do lado de dentro do estabelecimento - do(a) proprietário(a) do negócio. O próprio nome fantasia dos negócios, muitas vezes, remetiam ao Brasil ou Brazil, além de derivações do nome, bem como a lugares do Brasil (cidades) ou mesmo a expressões linguísticas regionais (por ex.: uai). Em restaurantes de comida brasileira, por exemplo, se é recepcionado em português, os cardápios estavam em português/inglês, e em alguns casos, a televisão se encontrava ligada em algum programa normalmente telejornal - de TV paga brasileira, ou se não fosse o caso, dentro do estabelecimento se ouvia música brasileira (por ex.: Bossa Nova, MPB etc.). Outro artefato visível, tem a ver com a decoração dos estabelecimentos, como quadros e fotos de lugares, povos e outros temas do Brasil, objetos regionais (artesanato) etc. De um modo geral, pode-se dizer que foi possível observar que a maioria da clientela nos locais visitados, nos momentos das observações in loco, era brasileira.

Tais observações, sugeriram, num primeiro momento, que vários desses negócios estavam a formar o que se poderia chamar de 'economia de enclave' (ZHOU, 2004), por vezes assumindo 
uma "feição" de empreendedorismo étnico, na medida em que pareciam visar um nicho de mercado dentro do comunidade (LIGHT, 1972). Ademais, a forte presença de símbolos de identificação étnica nos negócios - o que aqui se está a chamar de artefatos visíveis - reforçaram a impressão de que esses(as) empreendedores(as) tinham uma intensa identificação com o seu grupo étnico, e que portanto, estariam mais propensos a desenvolver 'estratégias de enclave' (ACHIDI-NDOFOR; PRIEM, 2011). Ainda, empreendedores imigrantes mais identificados com a sua comunidade étnica, estariam mais propensos a se tornarem empreendedores do 'enclave étnico' (LEE, 1999).

Para analisar essa questão com um pouco mais de precisão, buscou-se por meio da aplicação do questionário e das entrevistas, identificar dois pontos principais, entre outros aspectos: (i) a origem da maioria da clientela (mercado-alvo) do negócio/da empresa; (ii) o país de origem da maioria dos empregados. Como resultado do primeiro ponto, ou seja, a identificação da origem do público-alvo, tem-se que 59,46\% $(\mathrm{n}=22)$ indicaram ser "brasileiros residentes no Canadá", 24,33\% (n=9) "canadenses", 13,51\% $(n=5)$ "outros estrangeiros residentes" (principalmente portugueses e de origem hispano-americana) e 2,70\% $(\mathrm{n}=1)$ "turistas brasileiros", porém, de fato, quase todos os sujeitos das entrevistas pontuaram que a clientela é diversificada. No que se refere ao segundo item, a origem da mão de obra empregada no negócio, $71,43 \%(n=25)$ apontaram que eram brasileiros, por várias razões, a depender do ramo de atividade. No caso do ramo de beleza, por exemplo, o domínio da língua portuguesa é importante, assim como as habilidades técnicas da profissão, pois "brasileiros têm mais habilidade para lidar com alguns tipos de cabelo mais difíceis", conforme a fala de E27; para o ramo de serviços de limpeza, por exemplo, nem sempre é primordial ter um(a) empregado(a) brasileiro(a), haja vista que os negócios, na maior parte das vezes, não tem por foco "brasileiros residentes", conforme apontado por E14 (13 anos no Canadá) e E22 (17 anos no Canadá). Em ambos os ramos de atividades mencionados, os(as) brasileiros parecem de gozar de boa reputação, por exemplo, por serem "habilidosos", "versáteis", "flexíveis", "higiênicos" etc.

Como já dito, os resultados aqui apresentados são parciais, pois a coleta de dados primários ainda se encontra em andamento, assim como aspectos voltados a determinadas estratégias mercadológicas, ao papel do capital humanos, social e cognitivo no âmbito dos negócios, bem como o conhecimento dos participantes sobre o sistema de apoio governamental às small businesses, não chegaram a ser tratados neste trabalho.

\section{Considerações Finais}

O objetivo deste artigo foi analisar aspectos relativos ao perfil sociodemográfico da "comunidade" empreendedora brasileira em Toronto, seus traços comportamentais empreendedores, além dos negócios em si. Além disso, visa-se preencher lacuna de conhecimento sobre o empreendedorismo imigrante brasileiro no Canadá, a se iniciar pela GTA.

Sobre o perfil sociodemográfico dos participantes, tem-se que a maioria é proveniente da Região Sudeste (SP, MG e RJ), havendo ainda representantes das Regiões Sul, Nordeste, Centro Oeste e Norte, tendo os(as) mesmos(as) se autodeclarado, majoritariamente, brancos. A faixa etária predominante encontra-se de 35 a 39 anos, seguida de 40 a 44 anos, períodos da vida estes que representam potencial de alta produtividade do trabalho. A maioria dos participantes alegou ser casada e ter filhos. 
O nível de escolaridade dos participantes apresentou-se alta, com quase a metade de pósgraduados, em diversas áreas do conhecimento, principalmente em Administração. A proficiência em inglês também se mostrou alta, mas a de francês significativamente mais baixa. Tais características, potencialmente, podem trazer algumas implicações a uma eventual mobilidade interna.

A principal motivação para deixar o Brasil, tem a ver com "segurança" em um sentido amplo, além da busca de uma "melhor qualidade de vida". Tanto um estado de mal-estar social no Brasil - não somente hoje em dia -, quanto a eficácia do discurso oficial canadense, ao expressar um "país de oportunidades", "multicultural", "excelente nível educação" etc., parecem funcionar como fatores de "expulsão" e de "atração", respectivamente.

Pode-se considerar que a condição laboral da chegada se mostrou desfavorável, na medida em que a maioria apontou ter vindo "sem perspectiva de trabalho" e outros(as) "com emprego informal", portanto com um vínculo de trabalho fraco, portanto, tanto a primeira situação quanto a segunda, os(as) colocava numa situação de maior vulnerabilidade.

Toronto foi apontada como uma cidade cosmopolita, dinâmica e de oportunidades, uma cidade grande, mas bem organizada.

O perfil dos empreendedores de imigração mais recente, tem se mostrado com alta escolaridade, maior fluência em inglês, background profissional em escalões organizacionais mais altos, além de se interessarem e de terem proficiência com tecnologia, sendo alguns empreendedores à frente de startups na área de tecnologia. Aliás, startups em várias áreas de tecnologia têm sido atraídas e incentivadas por um forte ecossistema de empreendedorismo e inovação em Toronto e região.

A cidade de Toronto foi apontada como sede da maior parte dos negócios de imigrantes brasileiros, com destaque à concentração nas seguintes localidades: St. Claire Avenue West/Corso Italia-Davenport e Earlscourt e na Dundas Street West/Little Portugal. Parece que a região West End, tende a ser uma área com uma maior presença de negócios de imigrantes brasileiros, devido a uma zona de reconhecida residência de brasileiros.

De um modo geral, os negócios dos imigrantes brasileiros são de pequeno porte, sendo que a maioria atua no setor de prestação de serviços, em diversos ramos de atividade. Além disso, foi possível perceber, em vários negócios, uma forte busca de identificação com a própria comunidade étnica, o que pode sugerir a possível formação de uma 'economia de enclave' (em alguns ramos de atividade). Por outro lado, em determinados ramos de atividade, alguns negócios parecem visar o mercado mainstream, sem necessariamente excluir a comunidade brasileira local, ou mesmo a prestação de serviços no Brasil.

O presente estudo não dá conta das especificidades dos ramos de atividades dos negócios, uma vez que envolve empresas de setores/ramos diversos. Além disso, apesar da maioria dos participantes responderem que a empresa estava a funcionar formalmente registrada, vislumbrase que possa existir uma quantidade considerável de "negócios" que estejam na informalidade, e que se encontram, nesta pesquisa, sub representadas.

Portanto, com vistas a trabalhos futuros, sugere-se a realização de estudos segmentados por setor de atuação e/ou ramo de atividade, bem como pesquisas voltadas para os "negócios" que estejam a atuar informalmente.

\section{Referências}


ACHIDI-NDOFOR, H.; PRIEM, R.L. Immigrant entrepreneurs, the ethnic enclave strategy, and venture performance. Journal of Management, v. 37, n. 3, p. 790-818, 2011.

ALBA, R.D.; LOGAN, J.R. Minority proximity to whites in suburbs: An individual-level analysis of segregation. American Journal of Sociology, v. 98, n. 6, p. 1388-1427, 1993.

ALBA, R.; NEE, V. Rethinking Assimilation Theory for a New Era of Immigration1. The New Immigrant in American Society: Interdisciplinary Perspectives on the New Immigration, n. 2, 2014.

ALIAGA-ISLA, R.; RIALP, A. Systematic review of immigrant entrepreneurship literature: Previous findings and ways forward. Entrepreneurship \& Regional Development, v. 25, n. 9-10, p. 819-844, 2013.

ATKINSON, R.; FLINT, J. Accessing hidden and hard-to-reach populations: Snowball research strategies. Social Research Update, v. 33, n. 1, p. 1-4, 2001.

BAENINGER, R. Migrações transnacionais na fronteira: novos espaços da migração Sul-Sul. In BAENINGER, R.; CANALES, A. (Coords.). Migrações fronteiriças. Campinas, SP: Núcleo de Estudos de População "Elza Berquó" - Nepo/Unicamp, 2018.

BARDIN, L. Análise de conteúdo. Lisboa: Edições 70, 1977.

BAUER, M.W.; AARTS, B. Construção do corpus: um princípio para a coleta de dados qualitativos. In BAUER, M.W.; GASKELL, G. (Eds.). Pesquisa qualitativa com texto, imagem e som: um manual prático. Petrópolis, RJ: Vozes, 2002.

BONACICH, E. A theory of middleman minorities. American Sociological Review, p. 583594, 1973.

BONACICH, E. The other side of ethnic entrepreneurship: A dialogue with Waldinger, Aldrich, Ward and associates. International Migration Review, v. 27, n. 3, p. 685-692, 1993.

BOURDIEU, P. The forms of capital. In Richardson, J.F. (Ed.) Handbook of Theory and Research for the Sociology of Education. Greenword Press, 1986.

BRASIL. Ministério das Relações Exteriores. Brasileiros pelo mundo: estimativas populacionais, 2016. Disponível em: http://www.brasileirosnomundo.itamaraty.gov.br/acomunidade/estimativas-populacionais-dascomunidades. Acessado em: 04/03/2016.

CAMERON, E. Multiculturalism and immigration in Canada. Toronto: Canadian Scholar's Press, 2004.

CRUZ, E.P.; MANCEBO, R.C.; FALCÃO, R.P.Q. Empreendedorismo imigrante no contexto dos haitianos em Maricá: reflexões e propostas. Empreendedorismo, Gestão e Negócios, v. 7, n. 7, p. 143-159, 2018.

CRUZ, E.P.; FALCÃO, R.P.Q.; BARRETO, C.R. Exploring the evolution of ethnic entrepreneurship: the case of Brazilian immigrants in Florida. International Journal of Entrepreneurial Behavior \& Research, v. 24, n. 5, p. 971-993, 2018.

CRUZ, Eduardo Picanço; FALCÃO, Roberto Pessoa de Queiroz; BARRETO, Cesar Ramos (2017) Estudo exploratório do empreendedorismo imigrante brasileiro em Pompano Beach e Orlando - EUA, Revista Gestão e Planejamento, Salvador, 18, 37-54.

CRUZ, E.P.; FALCÃO, R.P.Q.; MANCEBO, R.C.; CASTRO, A.R.C. Trajetórias do empreendedorismo imigrante e estratégias de mercado a partir das experiências de brasileiros no exterior. Cadernos de Gestão e Empreendedorismo - CGE, v. 5, n. 2, p. 37-54, 2017. 
CRUZ, E.P.; FALCÃO, R.P.Q. Revisão bibliométrica no tema Empreendedorismo Imigrante e Étnico. Internext - Revista Eletrônica de Negócios Internacionais, v. 11, n. 3, p. 78-94, 2016.

DE HASS, H. Migration and development: A theoretical perspective. International Migration Review, v. 44, n. 1, p. 227-264, 2010.

DRORI, I.; HONIG, B.; WRIGHT, M. Transnational entrepreneurship: An emergent field of study, entrepreneurship theory and practice, v. 33, n. 5, p. 1001-1022, 2009.

EVANS, D.S.; LEIGHTON, L.S. Some empirical aspects of entrepreneurship. The American Economic Review, v. 79, n. 3, p. 519-535, 1989.

FALCÃO, R.P.Q.; CASTRO, A.R.C.; CRUZ, E.P.; AMARAL, S.S. Pequenos negócios e fluxo de informações em comunidades de imigrantes: ensaio sobre aplicação da netnografia. Cadernos de Gestão e Empreendedorismo - CGE, v. 6, n. 1, p. 30-45, 2018.

FIGUEIRA, R.R. Desde que fora de minhas fronteiras!" Controle Mediterrâneo e externalização europeia das demandas de refúgio. In BAENINGER, R.; CANALES, A. (Coords.). Migrações fronteiriças. Campinas, SP: Núcleo de Estudos de População "Elza Berquó" - Nepo/Unicamp, 2018.

FRAGA, M.V. Política de imigração do Canadá: diversificação étnica e integração econômica, In BÓGUS, L.; BAENINGER, R. (Orgs.). A nova face da emigração internacional no Brasil. São Paulo: EDUC, 2018.

GOZA, F. Brazilian imigration to North America. International Migration Review, v. 8, n. 1, p. 136-152, 1994.

GOZA, F. Brazilian immigration to Ontario. International Migration, v. 37, n. 4, p. 765-789, 1999.

GREENE, P. Ethnic sponsorship of business activities: A resource-based approach. Journal of Small Business Management, v. 35, n. 4, p. 58-71, 1997.

GULATI, S. Canada's small and medium-sized business owners: Diverse society in a microcosm, Special Report - TD Economics, October 12, p. 1-9, 2012.

HIEBERT, D. Canada: A false consensus? In KLOOSTERMAN, R.; RATH, J. (Eds.). Immigrant entrepreneurs: Venturing abroad in the age of globalization. Oxford, UK: Berg, 2003.

ICELAND, J.; WILKES, R. Does socioeconomic status matter? Race, class, and residential segregation. Social Problems, v. 53, n. 2, p. 248-273, 2006.

Innovation, Science and Economic Development Canada - ISED. "Key small business statistics - January 2019 edition", Web Service Centre - ISED, 2019. Available: www.ic.gc.ca/sbstatistics.

LEE, J. Retail niche domination among African American, Jewish, and Korean entrepreneurs: Competition, coethnic advantage and disadvantage. American Behavioral Scientist, v. 42, n. 9, p. 1398-1416, 1999.

LIGHT, I. Ethnic enterprise in America: Business and welfare among Chinese, Japanese, and Blacks. Los Angeles, CA: University of California Press, 1972.

Light, I. Disadvantaged minorities in self-employment. The International Journal of Comparative Sociology, v. 20, p. 31-45, 1979.LIGHT, I.; BHACHU, P.; KARAGEORGIS, S. Migration networks and immigrant entrepreneurship. California Immigrants in World Perspective: The Conference Paper, v. 1989-90, April 1990. 
LIGHT, I.; Rosenstein, C. Expanding the interaction theory of entrepreneurship. In PORTES, A. (Ed.). The Economic Sociology of Immigration: Essays on Networks, Ethnicity, and Entrepreneurship. New York: Russell Sage Foundation, 1995.

LOGAN, J.R.; ALBA, R.D.; McNULTY, T.L. Ethnic economies in metropolitan regions: Miami and beyond. Social Forces, v. 72, n. 3, p. 691-724, 1994.

MA, Z.; ZHAO, S.; WANG; T.; LEE; Y. An overview of contemporary ethnic entrepreneurship studies: Themes and relationships. International Journal of Entrepreneurial Behavior \& Research, v. 19, n. 1, p. 32-52, 2013.

MACHADO, M.M.; HOSSEIN, C.S. Empreendedores imigrantes brasileiros no exterior: uma oportunidade de Pesquisa em estudos organizacionais? V Congresso Brasileiro de Estudos Organizacionais - CBEO, Curitiba/PR, Universidade Federal do Paraná - UFPR, .2018.

MACHADO, M.M.; HOSSEIN, C.S.; CRUZ, E.P. Empreendedorismo imigrante no exterior: um olhar sobre os brasileiros residentes em Toronto (ON/CAN). Seminário Internacional de Tecnologia, Educação e Sociedade - Práticas em Gestão e Inovação, Itaquaquecetuba/SP, Fatec Itaquaquecetuba/Centro Paula Souza, 2019.

MARGOLIS, M.L. Little Brazil: imigrantes brasileiros em Nova York. Campinas, SP: Papirus, 1994.

MARGOLIS, M.L. Goodbye, Brazil: emigrantes brasileiros no mundo. São Paulo: Contexto, 2013.

MARTES, A.C.B. New immigrants, new land: A study of Brazilians in Massachusetts. Gainesville: University Press Florida, 2010.

MASUREL, E.; NIJKAMP, P.; TASTAN, M.; VINDIGNI, G. Motivations and performance conditions for ethnic entrepreneurship. Growth and Change, v. 33, n. 2, p. 238-260, 2002.

MINAYO, M.C.S. Trabalho de campo: contexto de observação, interação e descoberta. In MINAYO, M.C.S. (Org.). Pesquisa social: teoria, método e criatividade. 28. ed. Petrópolis, RJ: Vozes, 2009.

MOREIRA, T.O. A (necessária) proteção dos direitos humanos dos migrantes venezuelanos pela jurisdição brasileira. In BAENINGER, R.; CANALES, A. (Coords.). Migrações fronteiriças. Campinas, SP: Núcleo de Estudos de População "Elza Berquó” - Nepo/Únicamp, 2018.

NDOFOR, H.A.; PRIEM, R.L. Immigrant entrepreneurs, the ethnic enclave strategy, and venture performance. Journal of Management, v. 43, n. 5, p. 902-906, 2011.

NEE, V.; SANDERS, J.M.; SERNAU, S. Job transitions in an immigrant metropolis: ethnic boundaries and the mixed economy. American Sociological Review, p. 849-872, 1994.

PIÑEIRO, R.C.; LANDA, N. El muro fronterizo de Trump y la política migratória Estadounidense. In BAENINGER, R.; CANALES, A. (Coords.). Migrações fronteiriças. Campinas, SP: Núcleo de Estudos de População “Elza Berquó” - Nepo/Únicamp, 2018.

PORTES, A. 13 Modes of structural incorporation and present theories of labor immigration. International Migration Review, v. 15, n. 1, p. 279-297, 1981.

PORTES, A.; ZHOU, M. Gaining the upper hand: Economic mobility among immigrant and domestic minorities. Ethnic and Racial Studies, v. 15, n. 4, p. 491-522, 1992.

PORTES, A.; GUARNIZO, L.E.; HALLER, W.J. Transnational entrepreneurs: An alternative form of immigrant economic adaptation. American Sociological Review, p. 278-298, 2002. 
RATH, J. Introduction: Immigrant businesses and their economic, politico-institutional and social environment. In RATH, J. (Ed.), Immigrant businesses: The economic, political and social environment. Great Britain: Macmillan Press Ltd., 2000.

SALGADO, M.H.A. Los flujos migratórios y el control de las fronteras exteriores de la Unión Europea. In BAENINGER, R.; CANALES, A. (Coords.). Migrações fronteiriças. Campinas, SP: Núcleo de Estudos de População "Elza Berquó" - Nepo/Únicamp, 2018.

SASSEN, S. The mobility of labor and capital. Cambridge: Cambridge University Press, 1988.

SASSEN, S. The Global City: New York, London, Tokyo. Princeton, NJ: Princeton University Press, 1991.

SCHERVIER, Z. Brasileiros no Canadá: em busca de segurança? Interfaces Brasil/Canadá, Rio Grande, n. 5, p. 231-252, 2005.

SCHIMMELE, C.; WU, Z. The new immigration and ethnic identity. Population Change and Life Course Strategic Knowledge Cluster Discussion Paper Series/Un Réseau stratégique de Connaissances Changements de Population et Parcours de Vie Document de Travail, v. 3, n. 1, p. 1, 2015.

SEGA, R.F. Canadá em quatro tempos: o fluxo migratório de brasileiros para Toronto. In BÓGUS, L.; BAENINGER, R. (Orgs.). A nova face da emigração internacional no Brasil. São Paulo: EDUC, 2018.

SIMÕES, G.F. A mudança do perfil do imigrante venezuelano em Roraima e o aumento da xenofobia. In BAENINGER, R.; CANALES, A. (Coords.). Migrações fronteiriças. Campinas, SP: Núcleo de Estudos de População "Elza Berquó" - Nepo/Únicamp, 2018.

SUMMERS, D. The Economic Impact of Entrepreneurship. Academy of Entrepreneurship Journal, v. 21, n. 2, p. 99-108, 2015.

TRENZ, H-J.; TRIANDAFYLLIDOU, A. Complex and dynamic integration processes in Europe: Intra EU mobility and international migration in times of recession. Journal of Ethnic and Migration Studies, v. 43, n. 4, p. 546-559, 2017.

VEDOVATO, L.R. Do dream act ao muro - Direitos fundamentais diante da política partidária. In BAENINGER, R.; CANALES, A. (Coords.). Migrações fronteiriças. Campinas, SP: Núcleo de Estudos de População "Elza Berquó” - Nepo/Unicamp, 2018.

VERGARA, S.C. Projetos e relatórios de pesquisa em administração. 7. ed. São Paulo: Atlas, 2007.

WALDINGER, R.; ALDRICH, H.; WARD, R. Ethnic Entrepreneurs: Immigrant Business in Industrial Societies. London, UK: Sage, 1990.

WERBNER, P. From rags to riches: Manchester Pakistanis in the textile trade. New Community, v. 8, n. 1-2, p. 84-95, 1980.

WILSON, K.L.; PORTES, A. Immigrant enclaves: An analysis of the labor market experiences of Cubans in Miami. American Journal of Sociology, v. 86, n. 2, p. 295-319, 1980.

XIE, Y.; GOUGH, M. Ethnic enclaves and the earnings of immigrants. Demography, v. 48, n. 4, p. 1293-1315, 2011.

ZHOU, M. Revisiting ethnic entrepreneurship: Convergencies, controversies, and conceptual advancements. The International Migration Review, v. 38, n. 3, p. 1040-1074, 2004. 